\title{
Evaluation of personalized right ventricle to pulmonary artery conduits using in silico design and computational analysis of flow
}

Pegah Ebrahimi, MPhil, ${ }^{\mathrm{a}, \mathrm{b}}$ David Youssef, MBBS BPharm, ${ }^{\mathrm{b}}$ Gananjay Salve, MCh, ${ }^{\mathrm{b}}$ Julian Ayer, MBBS, FRACP, PhD, ${ }^{\text {b,c }}$ Fariba Dehghani, $\mathrm{PhD},{ }^{\mathrm{a}}$ David F. Fletcher, $\mathrm{PhD},{ }^{\mathrm{a}}$ and David S. Winlaw, MBBS, MD, FRACS ${ }^{\mathrm{a}, \mathrm{c}}$

\section{ABSTRACT}

Objectives: Right ventricle to pulmonary artery (RV-PA) conduits are required for the surgical management of pulmonary atresia with ventricular septal defect and truncus arteriosus. Bioengineered RV-PA connections may address some of the shortcomings of homografts and xenografts, such as lack of growth potential and structural deterioration and may be manufactured to accommodate patientspecific anatomy. The aim of this study was to develop a methodology for in silico patient-specific design and analysis of RV-PA conduits.

Methods: Cross-sectional imaging was obtained from patients with truncus arteriosus $(n=5)$ and pulmonary atresia with ventricular septal defect $(n=5)$ who underwent complete repair with a RV-PA conduit. Three-dimensional models of the heart were constructed by segmentation of the right ventricle, existing conduit, branch pulmonary arteries, and surrounding structures. A customized conduit design for each patient was proposed. Computational fluid dynamics analysis was performed and outputs, including wall shear stress and energy loss, were used to compare the performance of the existing conduits and the customized geometries.

Results: In this study, a methodology for patient-specific analysis of RV-PA conduit in silico was developed. The results of simulations for 10 patients showed between $23 \%$ and $56 \%$ decrease in the average wall shear stress and between $24 \%$ and $87 \%$ reduction in average power requirements in customized designs compared with the stenosed conduits, translating into better hemodynamic performance.

Conclusions: Creation of an optimal conduit for an individual patient can be achieved using surgeon-guided design and computational fluid dynamics analysis. Manufacture of personalized RV-PA conduits may obviate the need for surgical customization to accommodate existing materials and provide superior longterm outcomes. (JTCVS Open 2020;1:33-48)

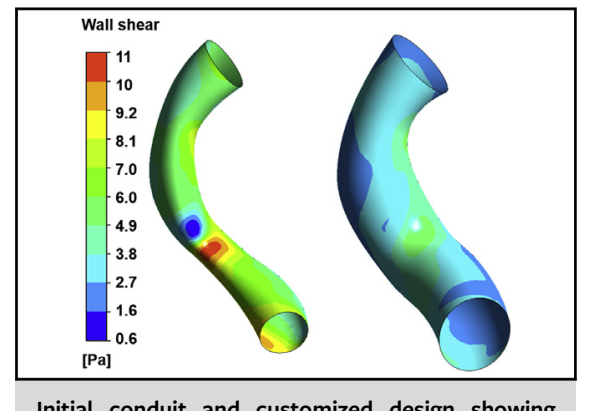

Initial conduit and customized design showing improved wall shear stress distribution.

\section{CENTRAL MESSAGE}

Patient-specific design and in silico testing of novel RV-PA conduits is feasible and will complement emerging RV-PA technologies.

\section{PERSPECTIVE}

Right ventricle to pulmonary artery conduits are an essential part of many pediatric cardiac reconstructions. We demonstrate that in silico patientspecific design and analysis of the proposed conduit is feasible. Iterative customization improves hemodynamic performance with potential benefits in reducing right ventricle work and durability. This approach may be employed with new generation polymer-based conduits.

See Commentary on page 49.

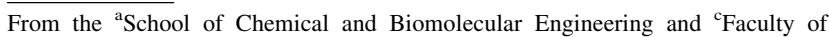
Medicine and Health, Discipline of Paediatrics and Child Health, Sydney Medical School, The University of Sydney, Sydney, Australia; and ${ }^{\mathrm{b}}$ Heart Centre for Children, The Children's Hospital at Westmead, Sydney, Australia.

Supported by The Wishaw Family Trust, a gift to the Heart Centre for Children.

Received for publication Nov 9, 2019; revisions received Nov 9, 2019; accepted for publication Feb 3, 2020; available ahead of print April 22, 2020.

Address for reprints: David S. Winlaw, MBBS, MD, FRACS, Heart Centre for Children, The Children's Hospital at Westmead, Locked Bag 4001, Corner Hawkesbury
Rd and Hainsworth St, Westmead, 2145, Sydney, Australia (E-mail: david. winlaw@sydney.edu.au).

2666-2736

Copyright $\odot 2020$ by The Authors. Published by Elsevier Inc. on behalf of The American Association for Thoracic Surgery. This is an open access article under the CC BY-NC-ND license (http://creativecommons.org/licenses/by-nc-nd/4.0/). https://doi.org/10.1016/j.xjon.2020.02.002 


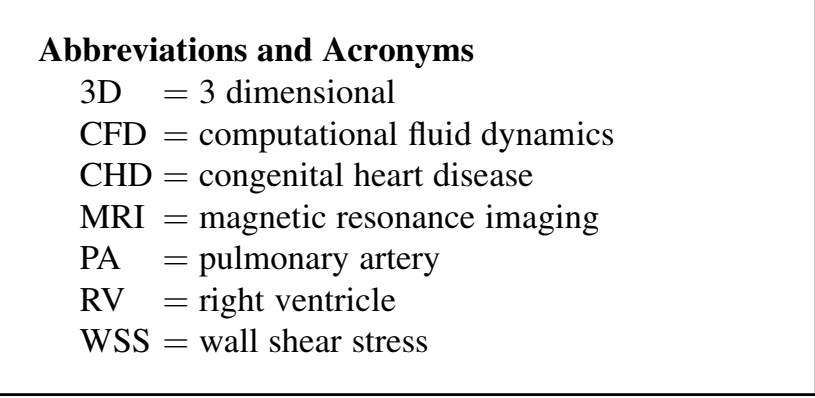

Video clip is available online.

Congenital heart disease (CHD) is the most common congenital disorder in newborn infants with a prevalence of approximately $1 \%$ of live births. About $25 \%$ of babies with CHD require surgery or other invasive procedures during their first year of life. A subset of these patients requires creation of a pathway between the right ventricle (RV) and pulmonary arteries (PAs) as part of the surgical repair, including patients with pulmonary atresia with ventricular septal defect and truncus arteriosus (TA).

Allograft and xenograft valved conduits are commonly utilized to create the RV-PA pathway. Such conduits do not grow and size mismatch between the patient and prosthesis develops over time, particularly when the initial implant is required during infancy. Hence, conduit replacement requiring repeated cardiac surgery and/or catheter procedures are necessary. Furthermore, implantation of homografts and xenografts requires additional operative customization to suit individual patient anatomy, including pericardial hoods and creation of nonideal pathways for blood flow, presumably resulting in substantial energy loss and biomechanical stresses that accelerate structural deterioration and accordingly, conduit dysfunction. The clinical context is explained in Video 1.

The ideal RV-PA valved conduit should have close to normal hemodynamic characteristics, resistance to structural deterioration, the capacity to grow in proportion to a patient's somatic growth, and be customized for each patient's anatomy. The use of tissue engineering in designing vascular grafts has gained momentum through the past decade. Several groups have vascular prostheses in preclinical and early human phases of evaluation. ${ }^{1-4}$ Moreover, the advance of 3-dimensional (3D) bioprinting has provided the potential for fabrication of patientspecific implants with complex geometries designed by computer. ${ }^{5,6}$

The geometrical design of the implant has substantial effects on its performance and durability in the body.

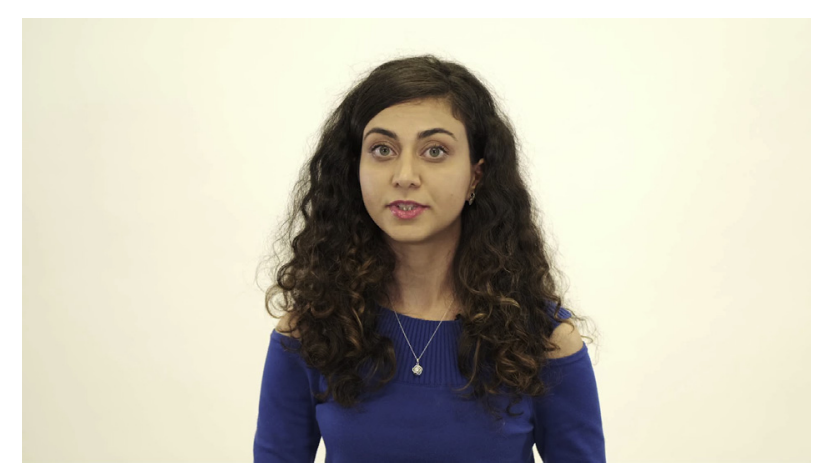

VIDEO 1. Dr Winlaw and Ms Ebrahimi discussing the study including methodology, outcomes, and clinical relevance. Video available at: https://www.jtcvs.org/article/S2666-2736(20)30004-8/fulltext..

Computational modeling allows evaluation of various designs by defining the expected hemodynamic performance of the conduit.

This study outlines a methodology for customization of the geometrical design of the RV-PA conduit using computational modeling. Although many investigators have utilized computational fluid dynamics (CFD) to evaluate the hemodynamic performance of nonvalved conduits for completion of total cavopulmonary connections, ${ }^{7-13}$ fewer studies have heeded the patientspecific aspects of the design ${ }^{14-17}$ and application of CFD in design of RV-PA conduits has rarely been reported. ${ }^{18}$ Herein, we detail an approach based on creating a model of individual patient anatomy derived from usual preoperative medical imaging, in children coming forward for first conduit replacement.

\section{METHODS \\ Patient Data}

Ten patients with existing RV-PA connections, 5 with pulmonary atresia/ventricular septal defect (patients A, B, C, D, and E) and 5 with TA (patients F, G, H, I, and J) were selected. All patients had imaging performed as part of assessments prior to replacement of their RV-PA connections. The data were collected under a protocol (2018/ ETH00683) approved by The Sydney Children's Hospital Network Ethics Committee.

Segmentation was performed on each patient's magnetic resonance imaging (MRI) or computed tomography data (DICOM files) using the Mimics inPrint 2.0 and Mimics research 20.0 software (Materialise, Leuven, Belgium) to create a 3D model of the heart. Results of segmentation on data from 10 patients are shown in Figure 1.

\section{Mechanical Model of the Conduit}

The STL file generated from segmentation process includes the 3D model of each region in the heart. This file was imported to Ansys SpaceClaim (Ansys, Concord, Mass) for further analysis. However, in its original form these data are not useful for simulation purposes because they contain details that may lead to computational complexity and nonphysical flows. Hence, we made a simplified model of the conduit that utilizes extracted curves and has the correct dimensions, while being smooth and therefore appropriate for computational purposes. Models were created by interpolating between several cross-sections (Figure 2, $B$ ) of the conduit extracted 

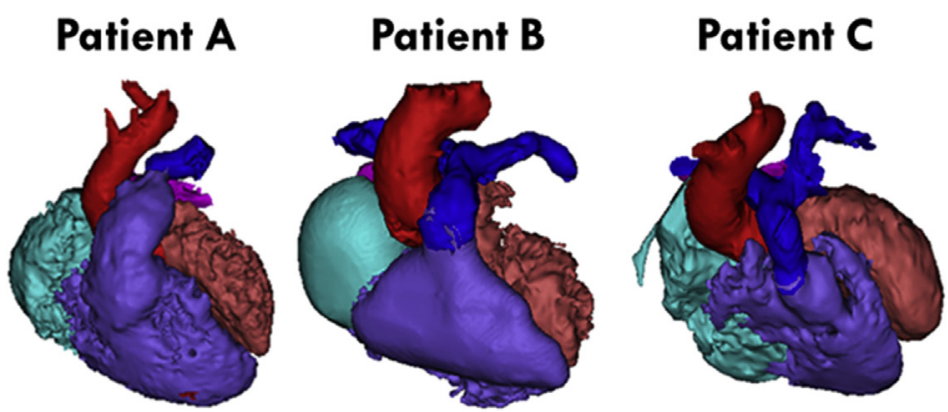

Patient D
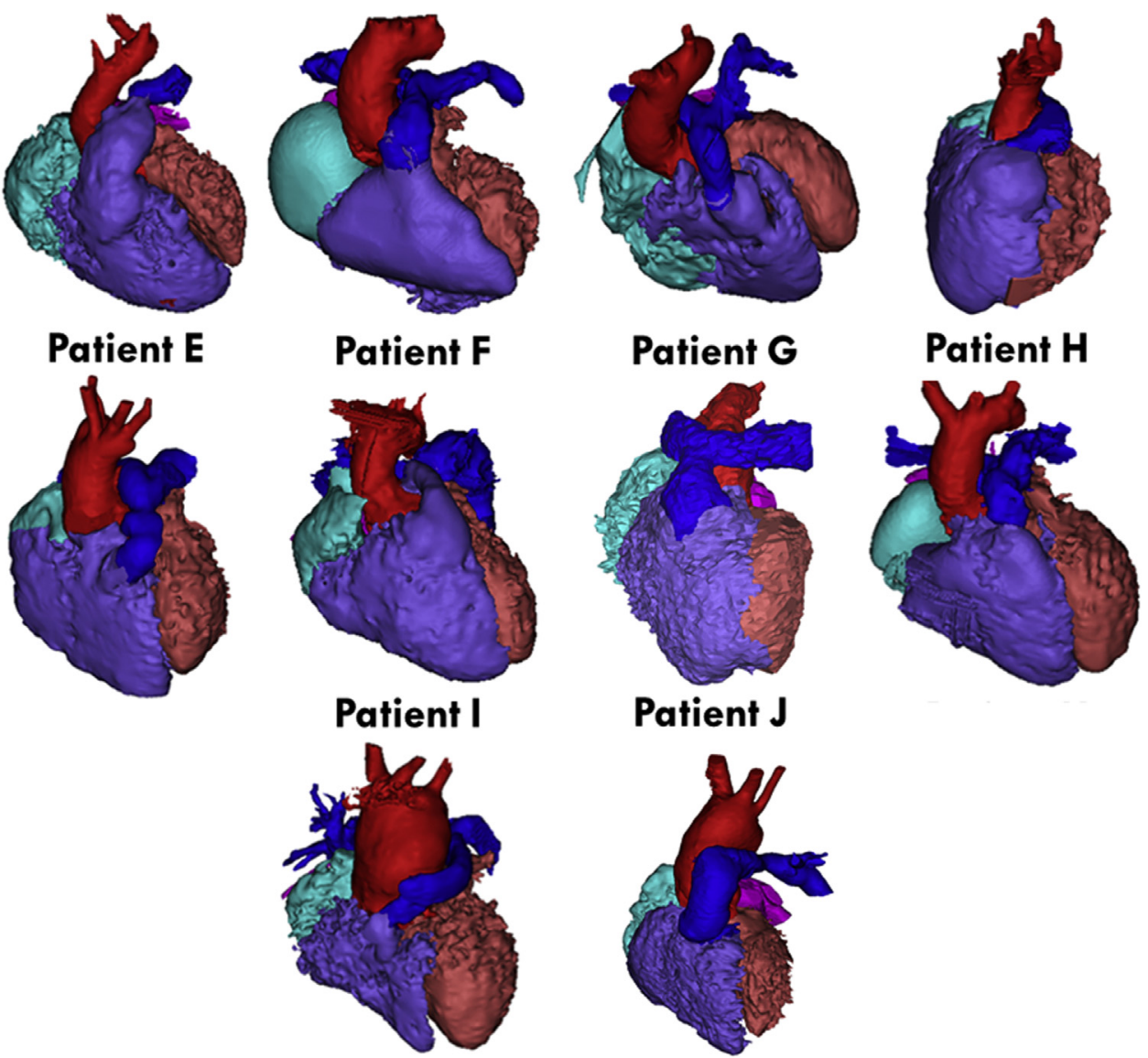

FIGURE 1. Three-dimensional models of the patients' hearts created by segmentation. Patients A-E, Pulmonary atresia with ventricular septal defect. Patients F-J, Truncus arteriosus.

from segmented models. The resulting geometries were modified iteratively to replicate the original shape. The models created by this method could approximate the original conduit shape to a satisfactory degree, while being simple and avoiding sharp area changes as much as possible (Figure 2, B, on the left). The geometry extraction process is demonstrated in Figure 2.

Our aim was to compare the performance of the current conduit with a proposed modified design. The first step was to choose a suitable diameter. The appropriate choice of the diameter of the implant conduit was based on weight, height, body surface area measurements, age, and gender. Using the method described elsewhere, ${ }^{19}$ the standard range for mid pulmonary artery for a normal heart was calculated. This can be an indicator of the appropriate diameter of RV-PA conduit. Taking into consideration the calculated standard range, the diameter of the current implant, and position of the aorta and sternum, the conduit was upsized to match the patient's somatic growth over time. The details of the parameters used in calculations and proposed diameter for each patient is demonstrated in Table 1.

After choosing the appropriate diameter, the centerline of the current conduit was extracted, and a constant cross-section was lofted along it. This assists with removing sharp curves and angles that might result in high shear stress and energy loss, while ensuring the pathway is physiologically feasible and is not restricted by the location of other organs. An example of an initial conduit and its associated modified geometry is shown in Figure 3.

\section{Simulation Process}

Fluid properties and boundary conditions. Blood flow through the geometry was assumed to be a 3D, time-dependent, incompressible, laminar flow. ${ }^{20}$ To model the non-Newtonian behavior of the blood, the Carreau-Yasuda model was employed. ${ }^{21}$

Equation 1:

$$
\mu(\dot{\gamma})=\mu_{\infty}+\left(\mu_{0}-\mu_{\infty}\right)\left[1+(\lambda \dot{\gamma})^{a}\right]^{(n-1){ }_{a}}
$$

where $\mu$ is the dynamic viscosity, $\lambda$ is a time constant, $n$ is the power law index, $a$ is the Yasuda exponent, $\dot{\gamma}$ represents a scalar measure of the rate of deformation or so-called shear rate, and $\mu_{0}$ and $\mu_{\infty}$ denote the viscosity at 0 and infinity shear rate, respectively. These parameters have been experimentally obtained to be: $\mu_{0}=0.056 \mathrm{~Pa} \mathrm{~s}, \mu_{\infty}=0.00345 \mathrm{~Pa} \mathrm{~s}$, $\lambda=1.902 \mathrm{~s}, n=0.22, a=1.25^{22}$

CFD simulations were performed using ANSYS CFX, version $19.2 .^{23} \mathrm{~A}$ patch-conforming method was used to generate a tetrahedral surface mesh and 5 layers of inflation with a growth rate of 1.2 and maximum thickness of $2.5 \mathrm{~mm}$ were applied at the walls (Figure 4). The target skewness was set to 0.6. A no-slip boundary condition was assigned at the walls of the conduit, and the velocity profile was imposed at the inlet. The outlet was defined as an opening and the relative pressure at the outlet was set to $0 \mathrm{~Pa}$.

The area-averaged velocity over time was acquired from patient echocardiograms and was converted to mass flow rate using the cross-sectional area at the location at which it was measured (Equation 2). 

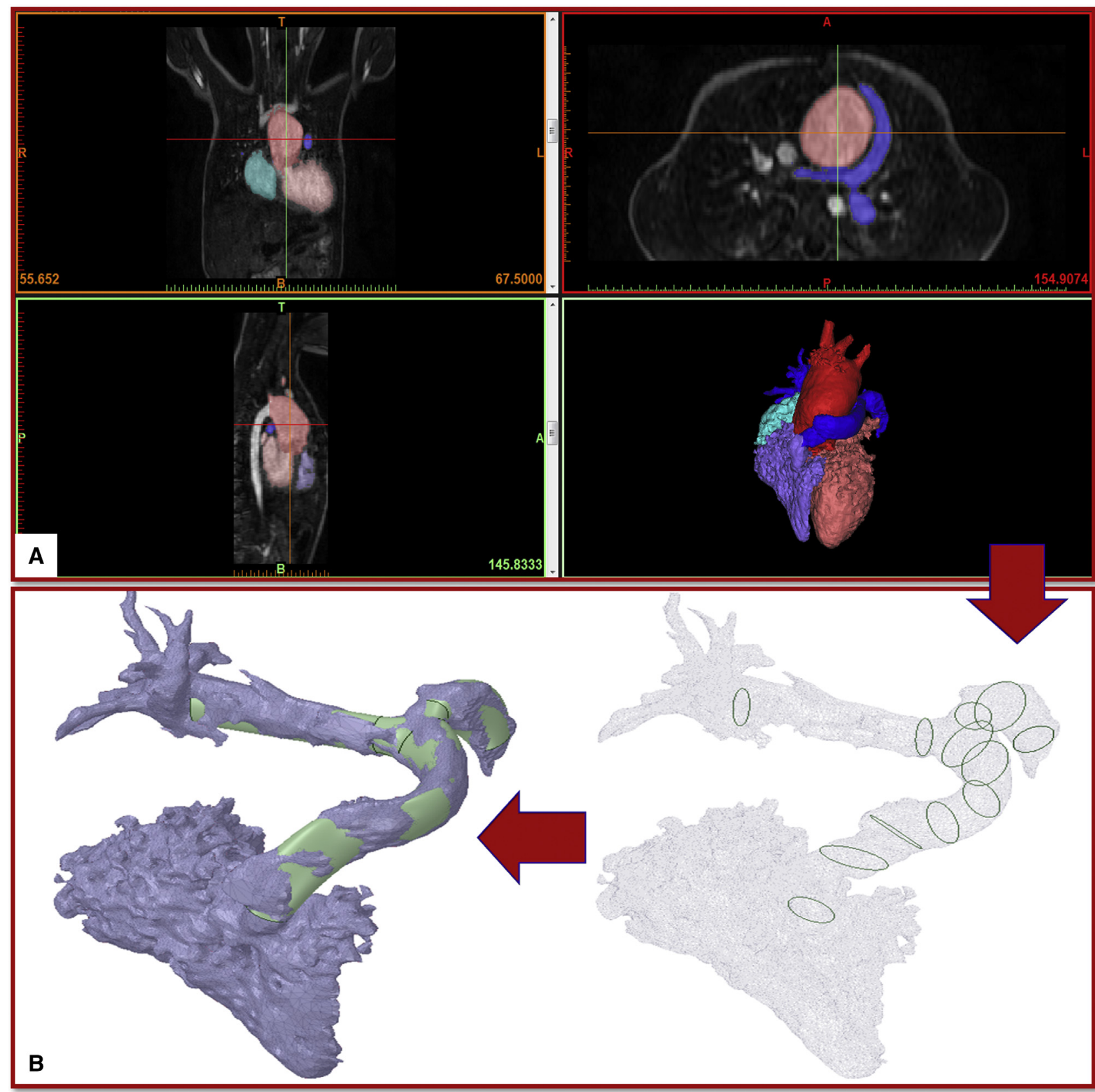

FIGURE 2. The geometry construction process. A, Constructing 3-dimensional model of the whole heart by performing segmentation on a patients' magnetic resonance imaging scan. B, Constructing conduit geometry by interpolating between extracted cross-sections. Right, Extracting crucial cross-sections. Left, The constructed geometry shows a good approximation of the original conduit.

Equation 2:

$$
\dot{m}=\rho \cdot \dot{V}=\rho \cdot v \cdot A
$$

where $\dot{m}$ is the mass flow rate, $\dot{V}$ is the volume flow rate, $v$ is the flow velocity, and $A$ is the cross-sectional area.

The same mass flow rate was applied to both the initial and modified conduits. This is a reasonable assumption, because the mass flow rate depends on the volumetric capacity of the RV, which is determined by physiological characteristics of the patients and will stay the same before and after the surgery. The velocity at the inlet for the initial and modified geometries is then set accordingly to yield the calculated mass flow.

As the full velocity data over time were not accessible, it was necessary to estimate these data. To this end, the peak positive and negative velocity and the rising and falling durations were extracted. In first attempts, the velocity curve with a triangular wave as of Figure 5 was approximated.

In this case, the sharp changes in the time-derivative of the velocity (at peak velocities and the beginning and end of each cycle) is not physiological and caused computational instability. To address this problem, the triangular wave was approximated by the first $n$ terms of its 
TABLE 1. Patient data used in diameter calculation

\begin{tabular}{|c|c|c|c|c|c|c|c|c|c|c|c|c|}
\hline Patient & Diagnosis & $\begin{array}{c}\text { Age at } \\
\text { first } \\
\text { conduit }\end{array}$ & $\begin{array}{l}\text { Type of first } \\
\text { conduit }\end{array}$ & $\begin{array}{c}\text { Size of } \\
\text { first } \\
\text { conduit } \\
(\mathbf{m m})\end{array}$ & $\begin{array}{c}\text { Age at } \\
\text { imaging } \\
\text { date }(y)\end{array}$ & $\begin{array}{c}\text { PR before } \\
\text { conduit } \\
\text { replacement } \\
(\% \mathbf{R F})\end{array}$ & $\begin{array}{c}\text { Time } \\
\text { elapsed } \\
\text { to conduit } \\
\text { replacement } \\
\text { (y) }\end{array}$ & $\begin{array}{c}\text { Height } \\
(\mathbf{c m})\end{array}$ & $\begin{array}{c}\text { Weight } \\
\text { (kg) }\end{array}$ & BSA & $\begin{array}{c}\text { Proposed } \\
\text { midPA } \\
\text { diameter } \\
\text { range } \\
(\mathrm{mm})\end{array}$ & $\begin{array}{c}\text { Proposed } \\
\text { conduit } \\
\text { diameter } \\
(\mathbf{m m})\end{array}$ \\
\hline A & PA/VSD & $25 \mathrm{mo}$ & $\begin{array}{l}\text { Bovine jugular } \\
\text { vein }\end{array}$ & 22 & 9 & Severe; 54 & 7 & 128 & 23.6 & 0.9 & $14.57-22.6$ & 22 \\
\hline B & $\mathrm{PA} / \mathrm{VSD}$ & $12 \mathrm{mo}$ & Aortic homograft & 19 & 10 & Moderate; 33 & 10.2 & 144 & 34 & 1.2 & $16.41-25.45$ & 19 \\
\hline $\mathrm{C}$ & $\mathrm{PA} / \mathrm{VSD}$ & $7 \mathrm{mo}$ & $\begin{array}{l}\text { Pulmonary } \\
\text { homograft }\end{array}$ & 12 & 9 & Moderate; 32 & 10.7 & 153 & 49 & 1.4 & $18.28-28.35$ & 22 \\
\hline D & PA/VSD & $7 \mathrm{mo}$ & $\begin{array}{l}\text { Nonvalved PTFE } \\
\text { conduit }\end{array}$ & 12 & 3 & Severe; 41 & 3.2 & 94 & 14.2 & 0.6 & $12.01-18.62$ & 16 \\
\hline E & $\mathrm{PA} / \mathrm{VSD}$ & $12 \mathrm{mo}$ & $\begin{array}{c}\text { Nonstented } \\
\text { xenograft } \\
\text { Medtronic } \\
\text { Freestyle* }\end{array}$ & 16 & 10 & Moderate; 32 & 10.8 & 132 & 30 & 0.7 & $15.61-24.22$ & 18 \\
\hline $\mathrm{F}$ & TA & $14 \mathrm{~d}$ & $\begin{array}{l}\text { Nonvalved PTFE } \\
\text { conduit }\end{array}$ & 10 & 3 & Severe; 43 & 2.9 & 84.3 & 11.4 & 0.5 & $11.1-17.21$ & 17 \\
\hline G & $\mathrm{TA}$ & $9 \mathrm{~d}$ & Aortic homograft & 12 & 4 & $\begin{array}{l}\text { Severe; } \\
\text { Not quantified }\end{array}$ & 4 & 80 & 10 & 0.5 & $10.61-16.46$ & 16 \\
\hline $\mathrm{H}$ & TA & $12 \mathrm{~d}$ & $\begin{array}{l}\text { Pulmonary } \\
\text { homograft }\end{array}$ & 10 & 8 & $\begin{array}{l}\text { Moderate; } \\
36\end{array}$ & 8.4 & 126 & 25.4 & 0.9 & $14.81-22.97$ & 18 \\
\hline I & TA & $3 d$ & $\begin{array}{c}\text { Nonvalved PTFE } \\
\text { tube conduit }\end{array}$ & 8 & 6 & Trivial; 3 & 6.2 & 112 & 18 & 0.7 & $13.22-20.51$ & 17 \\
\hline J & $\mathrm{TA}$ & $7 \mathrm{mo}$ & Aortic homograft & 15 & 4 & Moderate; 34 & 4.5 & 100 & 15.4 & 0.7 & $12.41-19.62$ & 16 \\
\hline
\end{tabular}

$P R$, Pulmonary regurgitation; $\% R F$, regurgitant fraction percent; $B S A$, body surface area; midPA, mid pulmonary artery; $P A / V S D$, pulmonary atresia with ventricular septal defect; $P F T E$, polytetrafluoroethylene; TA, truncus arteriosus. *Medtronic, Minneapolis, Minn.

Fourier series to obtain a smoother velocity profile. Figure 6 shows the triangular waveform estimated from echocardiogram of the test patient and the Fourier series approximations with various numbers of coefficients. As demonstrated, the difference between the curves with $n=3$, and $n=4$ is negligible. Hence, it sufficed to set $n=3$, which gives a 7-term Fourier series that was used for the test case. The number of coefficients of Fourier series that was used for each patient varies. The guideline is that the number of coefficients is increased until no significant change is noticed in 2 consecutive series.
Hemodynamic outputs. To compare the performance of the current conduits and proposed modified designs, output controls were set to monitor area-averaged wall shear stress (WSS) and energy dissipation rate. Energy-based metrics such as energy loss, ventricular stroke work and efficiency can integrate several hemodynamic indicators, for instance pulmonary flow and pressure data, into a single parameter. In this study, mechanical energy dissipation rate was selected as an energy-based metric and was calculated as described by Ebrahimi. ${ }^{24}$

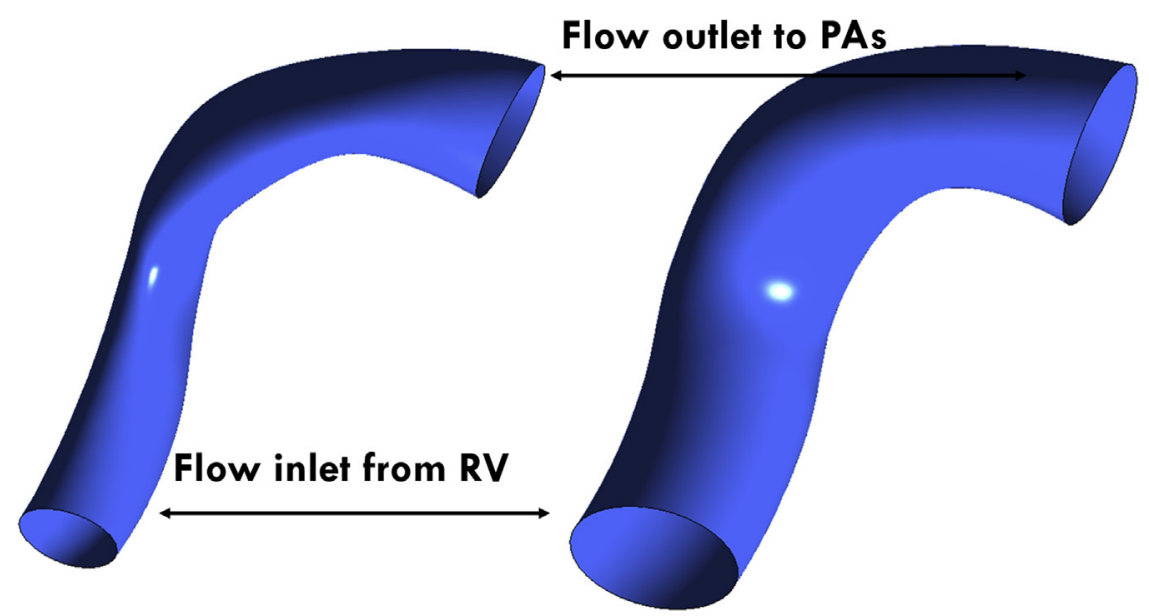

FIGURE 3. An example of geometry modification. Left, Initial conduit. Right, Proposed geometry. PA, Pulmonary artery; $R V$, right ventricle. 


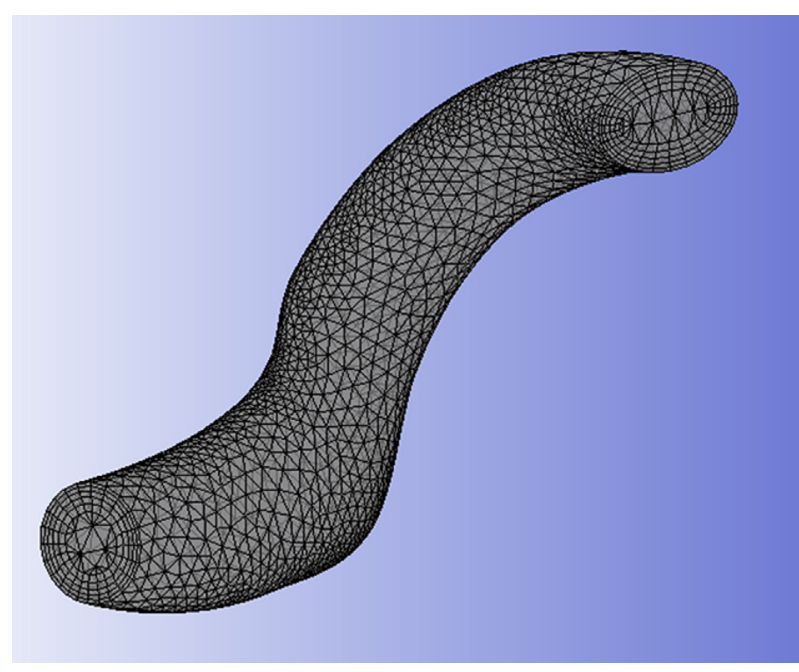

FIGURE 4. An example of surface meshing on 1 of the geometries.

It was also necessary to introduce metrics to measure the scale of changes in these factors. Hence, the effective WSS on the conduit wall per unit area per unit time was calculated using the equation:

Equation 3:

$$
\text { Effective WSS }=\frac{\int_{\tau} \mathrm{WSS}_{\mathrm{Ave}} \mathrm{dt}}{\tau}
$$

where $W S S_{\text {Ave }}$ is the area-averaged WSS and $\tau$ is the period of the cardiac cycle. This equation gives the time and area-averaged WSS over a cardiac cycle.

The average power loss over a cardiac cycle was calculated as below: Equation 4:

Average power loss $=\frac{\int_{\tau}(\text { rate of energy dissipation }) \mathrm{dt}}{\tau}$
Mesh and time-step independence studies were performed to confirm the computational validity of the results. ${ }^{24}$ In all cases, the simulations were performed for 3 cycles to allow developed results that do not contain start-up effects, and the results are shown for the last cycle.

\section{RESULTS}

Results, shown in Figures 7 and 8, suggest that the modification of the conduit design assisted in decreasing the rate of energy dissipation and WSS, respectively, for all 10 patients.

WSS changes proportionate to the magnitude of the tangential forces caused by the flow affecting the wall regardless of their direction, hence in Figure 8, 2 peaks are noticed for WSS at points where maximum inward and outward flow happens.

For patient F, it was noticed that different results were produced from those of other patients. The first proposed modification of the geometry with a diameter of $17 \mathrm{~mm}$, increased the area-averaged WSS contrary to expectations. Hence, a second modification of the geometry was proposed using the same curves and angles but with an enlarged diameter of $19 \mathrm{~mm}$. This time, similar results to other patients were observed in accordance with expectations.

This case accentuates the crucial influence of the diameter of the conduit on important hemodynamic factors. In addition, it underscores the importance of patient-specific modeling in design of the modified implant. Here, the hypothesized appropriate diameter did not enhance the performance of the implant; hence, a second geometry was proposed to resolve this issue. This was impossible to foresee without the employment of a patient-specific

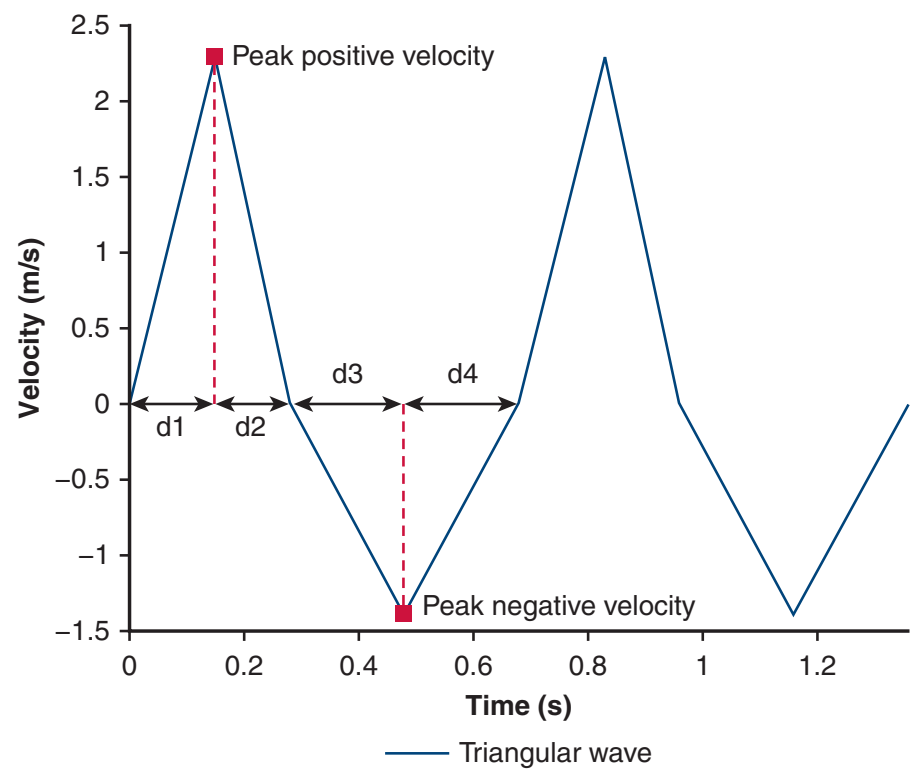

FIGURE 5. Demonstration of the parameters that define the velocity curve. 


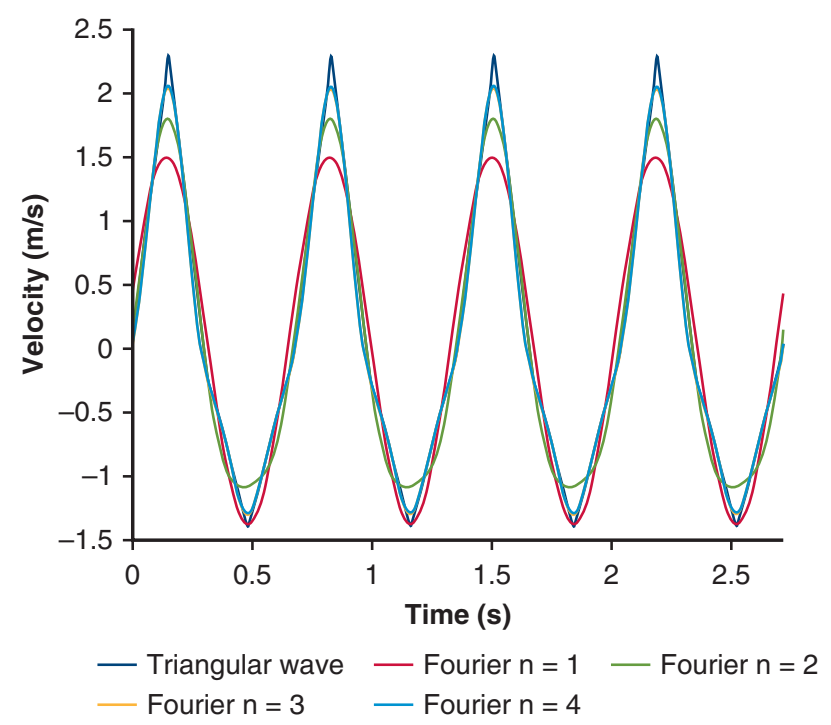

FIGURE 6. Triangular velocity waveform and its Fourier series approximation for different number of terms. In this case, $n=3$ provides sufficient accuracy.

model. Lastly, the 3D model of the heart ensures that a patient's anatomy can accommodate the proposed conduit geometry.

Figure 9 illustrates typical distributions of WSS at the beginning of a cardiac cycle for the initial and modified conduit geometries for all 10 patients. The decrease in WSS in modified geometries is also apparent here.

The values of effective WSS and average power loss as described above were estimated for the initial and modified geometries for each patient. The improvement of these parameters for the modified geometries compared with the initial geometries was also calculated. Results are summarized in Table 2.

From Table 2 it can be seen that the geometry modification process resulted in between $23 \%$ and $56 \%$ decrease in the effective WSS and between $24 \%$ and $87 \%$ reduction in average power loss and in turn RV work. The extent to which reductions in RV work and WSS are associated with improved conduit durability and other benefits are yet to be quantified.

To account for deformability of the artery wall and its effect on the WSS, 1-way fluid solid interaction analysis was performed on initial and modified geometries of each patient (Appendix 1). Results from this study reconfirmed the conclusions made in this section.

\section{DISCUSSION}

This work aimed to develop a methodology for patientspecific design and evaluation of the RV-PA implant using computational modelling. Proof of concept is provided that can be extended in the future with the ultimate goal of $3 \mathrm{D}$ printing customized conduits for each patient to be used during conduit replacement surgery and possibly primary implantation.

Integration of clinical data with engineering techniques allowed construction of patient-specific models that enabled in silico evaluation of the conduit through CFD analysis. A methodology for extracting implant geometry from segmented medical images of the heart and modifying its geometrical design considering the anatomy and clinical data of patients was advanced.

Simulation of blood flow through the initial and modified geometries showed significant improvements in WSS and mechanical energy dissipation for the modified geometries. WSS and its minimization in conduit design is central to slowing structural deterioration. High conduit-associated energy loss may lead to progressive RV dysfunction, particularly because the conduit is outgrown or becomes stenotic. Determination of the stress distribution identifies the points at which the implant is more susceptible to structural deterioration and hence reduced durability.

For 10 patients in this study, average WSS on the conduit wall was reduced by between $23 \%$ and $56 \%$ and average power loss was reduced by between $24 \%$ and $87 \%$ as a result of design modification process. Although decreases in WSS and energy loss are expected when replacing a stenosed conduit with a larger conduit, such changes are not quantified in standard clinical practice and changes in shape as well as diameter are required to achieve an optimal result. Moreover, the scale of improvement in these features shows a wide range due to large interpatient variability. This accentuates the importance of patient-specific modeling and surgical planning. Having the tools to evaluate these variables in silico, the geometrical design can iteratively be modified to achieve optimal performance for each patient. This can help to transform the current 1-size-fits-all clinical practice. For instance, an improvement of less than a certain percentage might not be worth the replacement procedure with all its attendant risks.

An index of energy loss may provide an additional tool for better timing of the replacement of a conduit. With current approaches, replacement of RV-PA conduits is unavoidable for patients with a reconstructed RV outflow tract. The underlying factors that necessitate the replacement of the conduit include valve incompetence, regurgitation, stenosis, and above all conduit obstruction. It is intuitive that all these attributes contribute to mechanical energy loss. Hence, the methodology developed for evaluation of energy dissipation over the conduit could, in the future, be employed to calculate an index of energy loss, as an aid in monitoring of patients with a conduit and to guide the timing of replacement.

Currently, further investigations to guide timing of reoperation for conduit stenosis are triggered by echocardiography measurements of RV to PA pressure gradient 

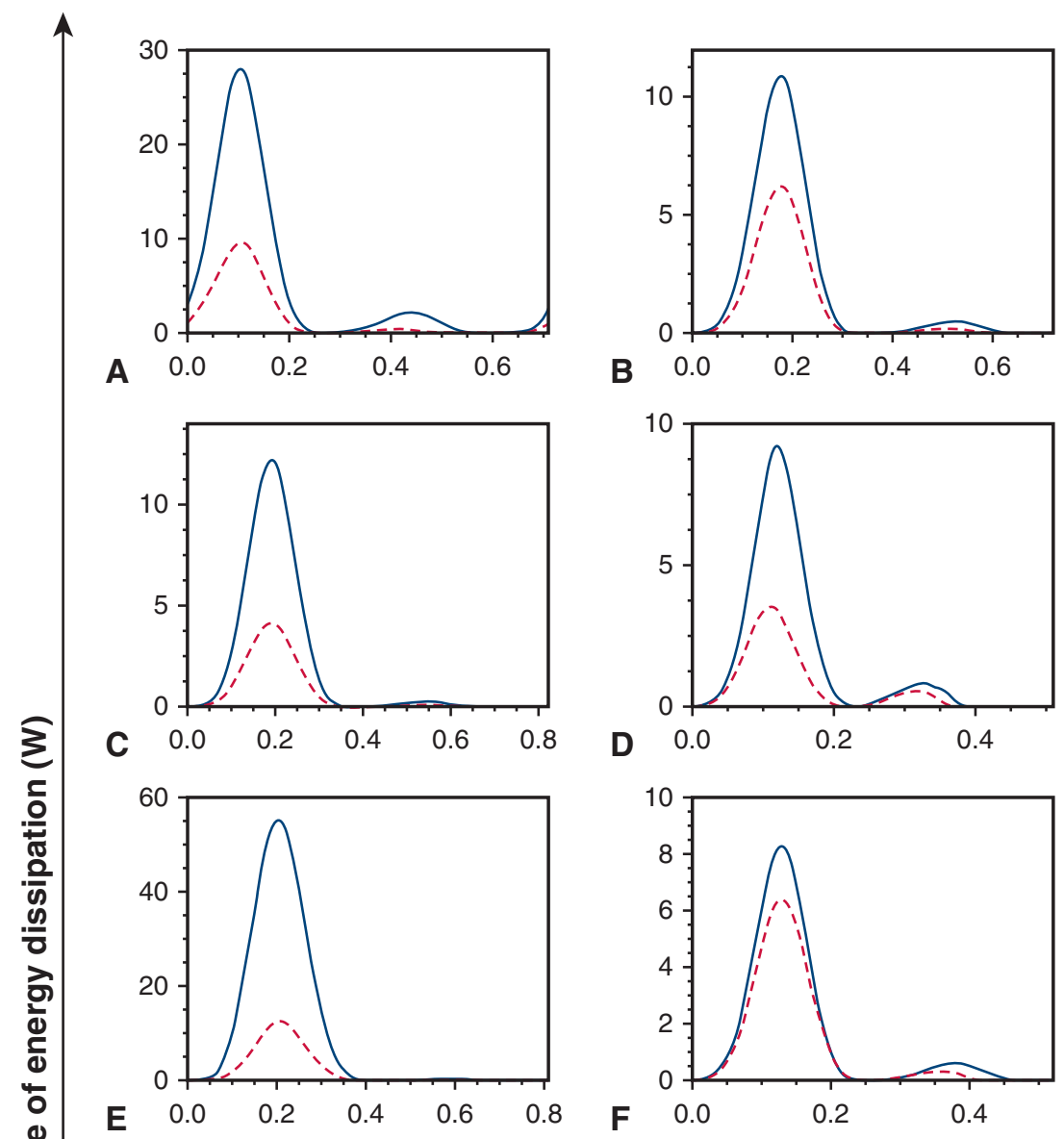

D 0.0
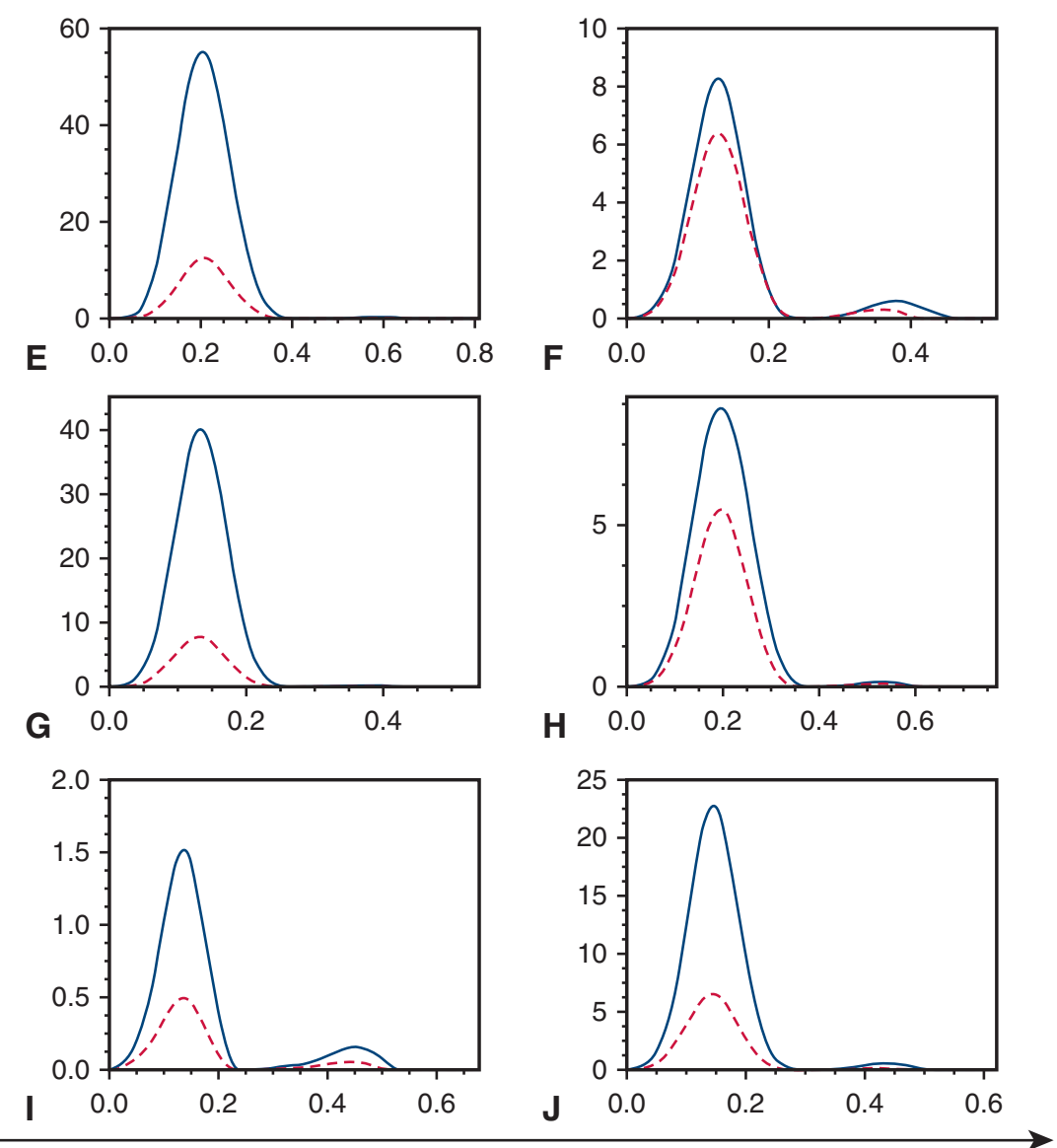

Simulation time (s)

— Initial geometry - - - Modified geometry

FIGURE 7. Comparison of rate of energy dissipation through the initial implants and proposed modified geometries over a cardiac cycle for patients A through J. 

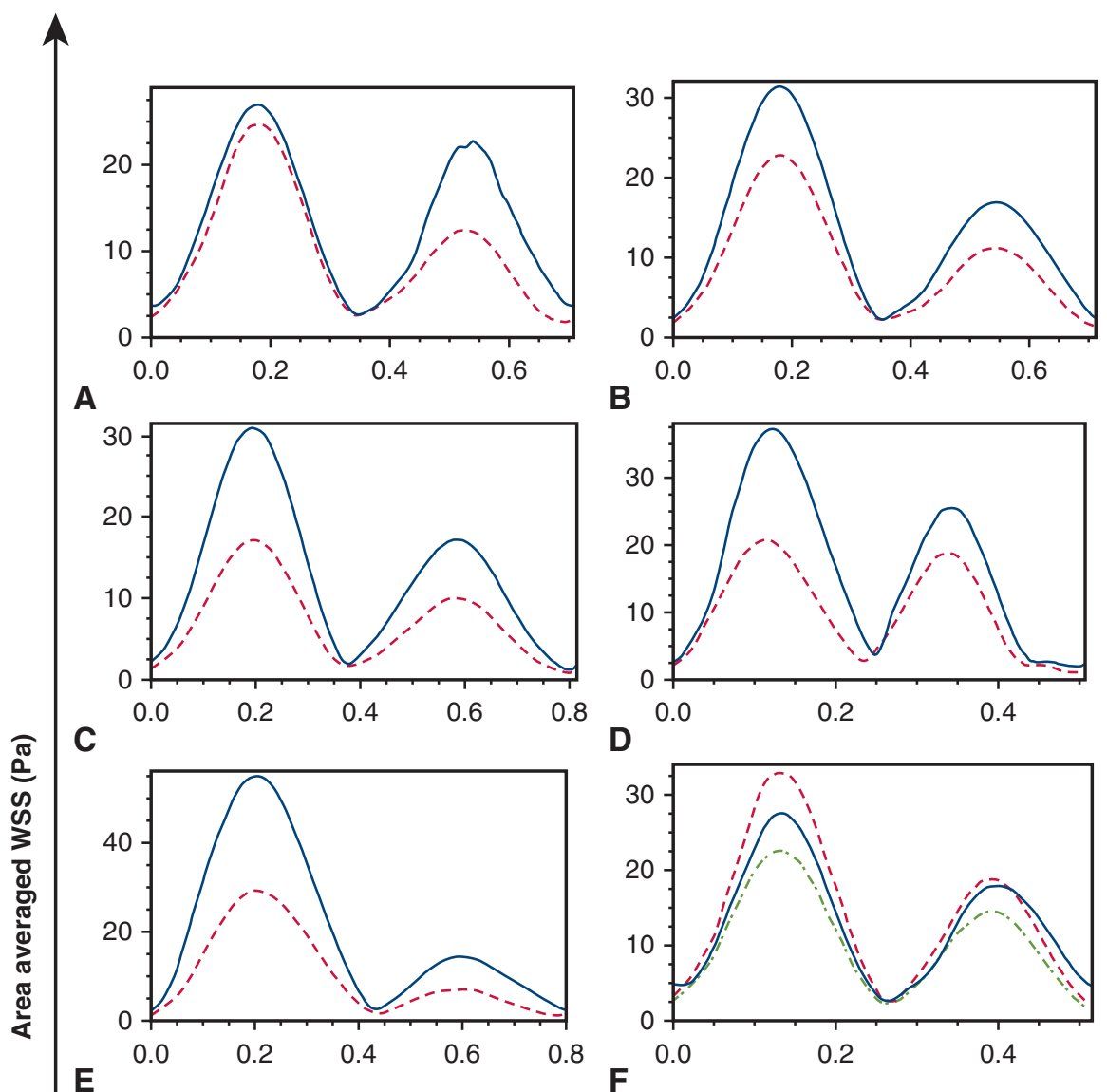

D
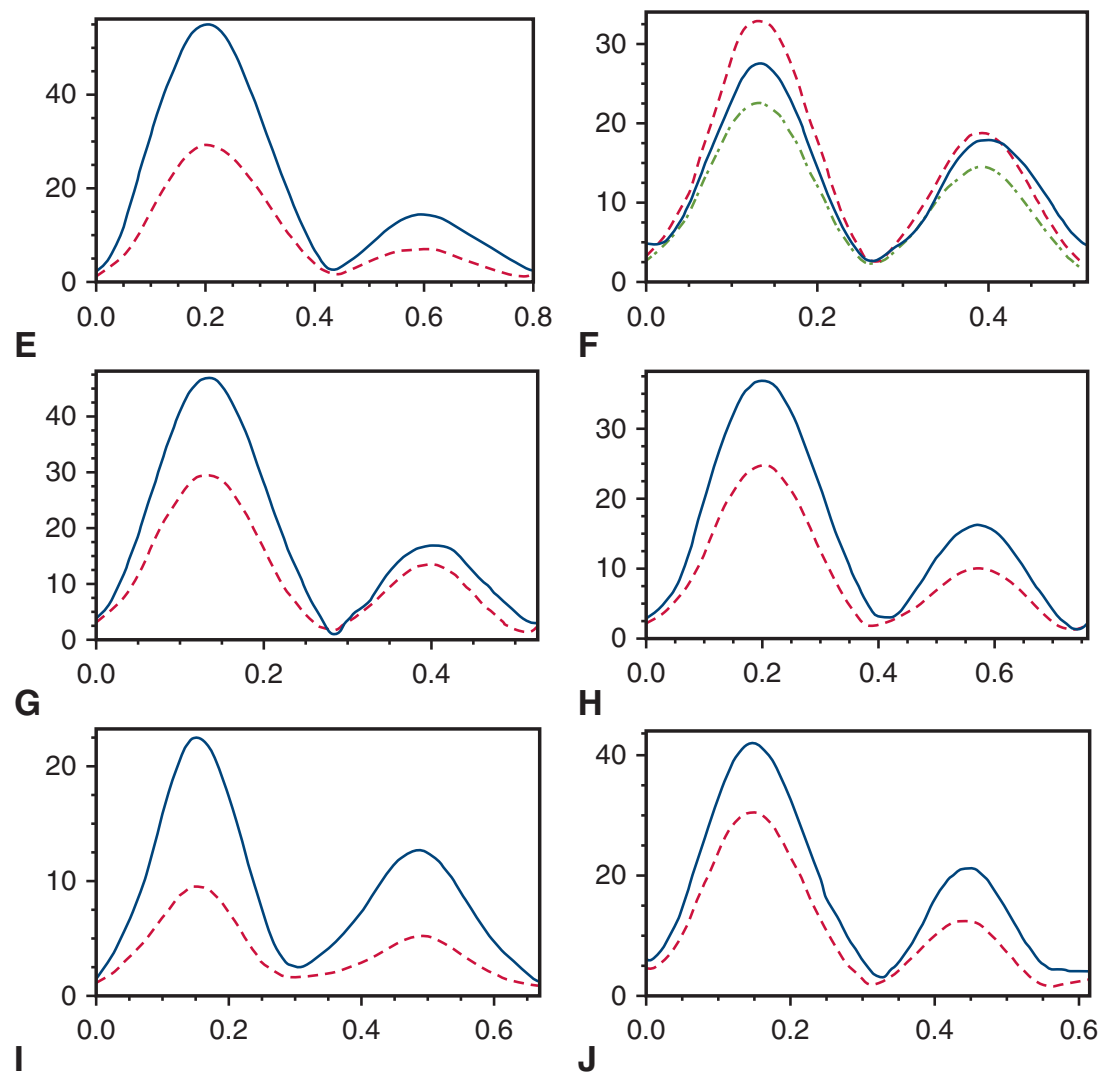

Simulation time (s)

Initial geometry - - - - Modified geometry -...-. Modified geometry 2

FIGURE 8. Comparison of area-averaged wall shear stress (WSS) on the initial implants and proposed modified geometries over a cardiac cycle for patients A through $\mathrm{J}$.

(pressure gradient over the conduit), or the ratio of RV systolic pressure to LV systolic pressure. ${ }^{25}$ These are all subjective and sometimes not easily replicated between observers, and echocardiography windows can be poor for some patients. MRI provides detailed information regarding the specific nature of conduit dysfunction (stenosis and/or 


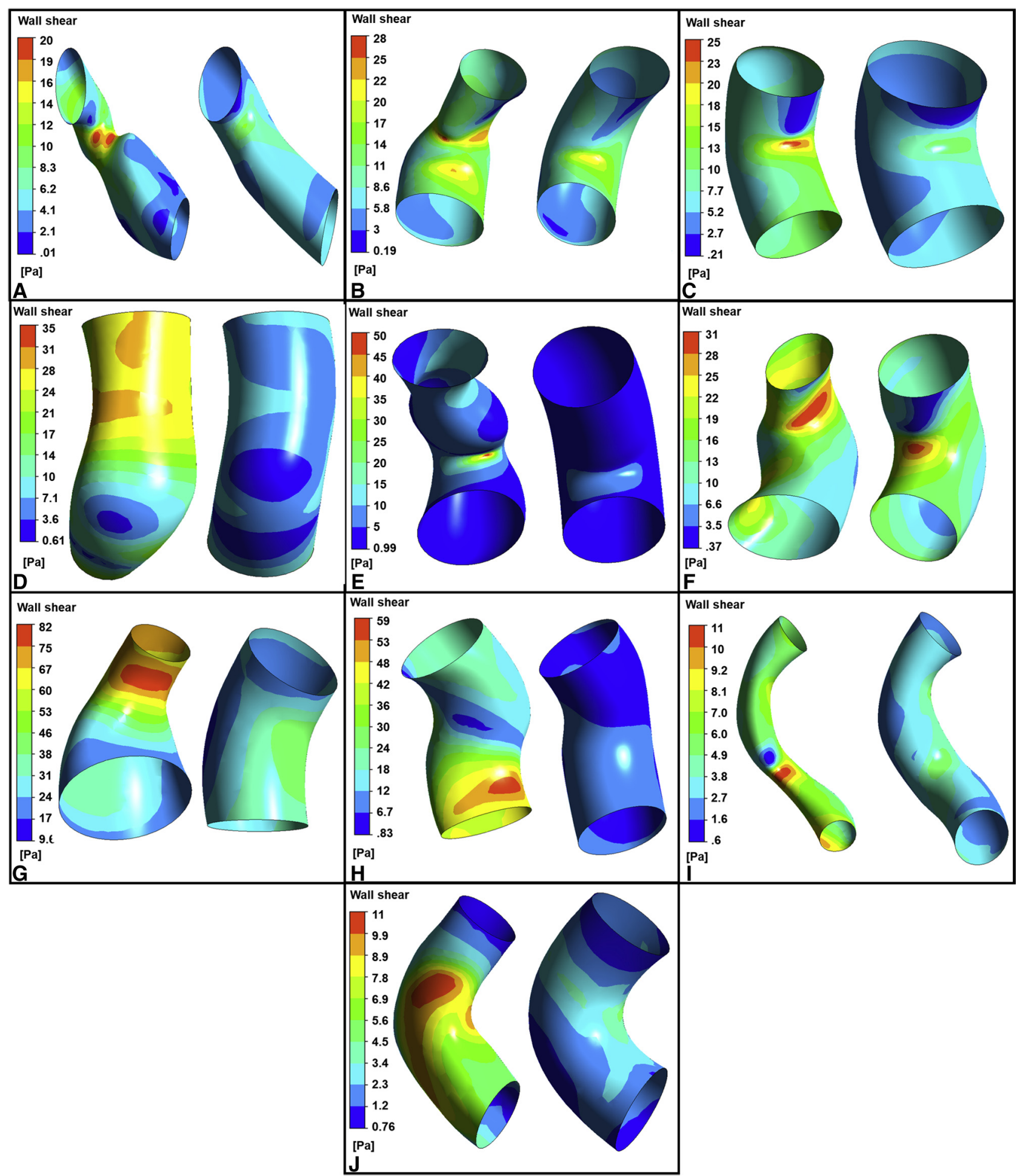

FIGURE 9. Comparison of wall shear stress (WSS) distribution between initial (left) and modified geometries (right) for patients A though J at the beginning of the cardiac cycle.

regurgitation) and defines RV size and function. An index of energy loss may have clinical utility, because it incorporates all the elements that combine to produce conduit failure. If serial MRIs were done, an index of energy loss could guide timing of reoperation before the development of RV failure, because symptoms of excessive RV work appear late and are usually nonspecific; for instance, fatigue and exercise intolerance. 
TABLE 2. Comparison of effective wall shear stress (WSS) and average power loss per cycle as described above for initial and modified geometries for all 10 patients

\begin{tabular}{|c|c|c|c|c|c|c|}
\hline Patient & $\begin{array}{c}\text { Effective WSS } \\
\text { on initial } \\
\text { geometry }(\mathbf{P a})\end{array}$ & $\begin{array}{c}\text { Effective WSS } \\
\text { on modified } \\
\text { geometry (Pa) }\end{array}$ & $\begin{array}{c}\text { Average power loss } \\
\text { in initial } \\
\text { geometry }(\mathrm{W})\end{array}$ & $\begin{array}{l}\text { Average power loss } \\
\text { in modified } \\
\text { geometry }(W)\end{array}$ & $\begin{array}{c}\text { Reduction } \\
\text { in effective } \\
\text { WSS }(\%)\end{array}$ & $\begin{array}{c}\text { Reduction } \\
\text { in average } \\
\text { power loss }(\%)\end{array}$ \\
\hline A & 13.39 & 9.97 & 5.13 & 0.650 & 25 & 87 \\
\hline B & 13.46 & 9.41 & 1.92 & 1.07 & 30 & 44 \\
\hline $\mathrm{C}$ & 12.8 & 7.26 & 1.99 & 0.423 & 43 & 78 \\
\hline D & 16.3 & 10.2 & 1.61 & 0.645 & 37 & 60 \\
\hline $\mathrm{E}$ & 20.3 & 10.5 & 9.96 & 2.16 & 48 & 78 \\
\hline $\mathrm{F}$ & 13.02 & 10.58 & 1.54 & 1.17 & 23 & 24 \\
\hline G & 18.1 & 11.82 & 6.99 & 1.38 & 35 & 80 \\
\hline $\mathrm{H}$ & 14.93 & 9.54 & 1.65 & 0.977 & 36 & 40 \\
\hline I & 9.2 & 4.03 & 0.247 & 0.078 & 56 & 68 \\
\hline $\mathrm{J}$ & 17.2 & 11.5 & 3.93 & 1.14 & 33 & 71 \\
\hline
\end{tabular}

WSS, Wall shear stress.

\section{Limitations}

This work is performed in silico and results require validation in the clinical domain. An inherent limitation of this study is the use of preoperative boundary conditions for evaluating the performance of a proposed modified conduit. Hence, prospective paired analyses of conduit performance before and after replacement is needed to validate the conclusions. Correlation of noninvasive assumed values with invasively measured data in a subset of patients and/or animal models is also required. Moreover, the influence of the valve on flow, energy dissipation, and WSS distribution needs to be investigated. In most patients requiring conduit replacement, there is substantial valve dysfunction, and this may also occur early postoperatively, especially in homografts. In addition to the conduit design, computational modelling can play a significant role in valve design.

\section{CONCULSIONS}

In this study, hemodynamic improvements of a proposed modification of a current clinically used conduit was demonstrated. Furthermore, the modified geometry was lofted along the centerline of the current conduit. This is not the only design that is feasible; hence, the performance of several independent geometrical designs for each patient may also be studied and compared in the future to achieve the ideal design.

\section{Conflict of Interest Statement}

The authors reported no conflicts of interest.

The Journal policy requires editors and reviewers to disclose conflicts of interest and to decline handling or reviewing manuscripts for which they may have a conflict of interest. The editors and reviewers of this article have no conflicts of interest.

The authors thank Dr Iman Manavi-Tehrani for measuring the mechanical properties of donor human pulmonary arterial wall that was used for fluid-solid interaction analysis in this study and Dr Jing Zhao for assistance in manuscript preparation.

\section{References}

1. Stowell CE, Wang Y. Quickening: translational design of resorbable synthetic vascular grafts. Biomaterials. 2018:173:71-86.

2. ClinicalTrials.gov identifier NCT03022708.

3. TEH-TUBE. Tissue engineering of the right heart outflow tract by a biofunctionalized bioresorbable polymeric valved tube. Available at: https://www. teh-tube.eu. Accessed April 1, 2019.

4. Drews JD, Miyachi H, Shinoka T. Tissue-engineered vascular grafts for congenital cardiac disease: clinical experience and current status. Trends Cardiovasc Med. 2017;27:521-31

5. Lee W, Hong Y, Dai G. 3D bioprinting of vascular conduits for pediatric congenital heart repairs. Translation Res. 2019:211:35-45.

6. Mandrycky C, Wang Z, Kim K, Kim DH. 3D bioprinting for engineering complex tissues. Biotechnol Adv. 2016;34:422-34.

7. Dasi L, Pekkan K, Katajima HD, Yoganathan AP. Functional analysis of Fontan energy dissipation. J Biomech. 2008;41:2246-52.

8. Trusty PM, Slesnick TC, Wei ZA, Rossignac J, Kanter K, Fogel MA, et al. Fontan surgical planning: previous accomplishments, current challenges, and future directions. J Cardiovasc Transl Res. 2018;11:133-44.

9. Soerensen DD, Pekkan K, Zélicourt DA, Sharma S, Kanter K, Fogel M, et al. Introduction of a new optimized total cavopulmonary connection. Ann Thorac Surg. 2007;83:2182-90.

10. Zelicourt DA. A Mechanical Fluid Assessment of Anatomical Models of the Total Cavopulmonary Connection (TCPC). [doctoral dissertation]. Atlanta, GA: Georgia Institute of Technology; 2004.

11. Yang W, Feinstein JA, Shadden SC, Vignon-Clementel IE, Marsden AL. Optimization of a Y-graft design for improved hepatic flow distribution in the Fontan circulation. J Biomech Engineer. 2013;135:011002.

12. Yang W, Chan FP, Reddy VM, Marsden AL, Feinstein JA. Flow simulations and validation for the first cohort of patients undergoing the Y-graft Fontan procedure. J Thorac Cardiovasc Surg. 2015;149:247-55.

13. Tang E, Yoganathan AP. Optimizing hepatic flow distribution with the Fontan Ygraft: lessons from computational simulations. J Thorac Cardiovasc Surg. 2015; 149:255-6. 
14. Siallagan D, Loke YH, Olivieri L, Opfermann J, Ong CS, de Zélicourt D, et al. Virtual surgical planning, flow simulation, and 3-dimensional electrospinning of patient-specific grafts to optimize Fontan hemodynamics. J Thorac Cardiovasc Surg. 2018;155:1734-42.

15. Capelli C, Sauvage E, Giusti G, Bosi GM, Ntsinjana H, Carminati M, et al. Patient-specific simulations for planning treatment in congenital heart disease. Interf Focus. 2017;8:20170021.

16. van Bakel TM, Lau KD, Hirsch-Romano J, Trimarchi S, Dorfman AL, Figueroa CA. Patient-specific modeling of hemodynamics: supporting surgical planning in a Fontan circulation correction. J Cardiovasc Transl Res. 2018;11: 145-55.

17. Zélicourt DA, Kurtcuoglu V. Patient-specific surgical planning, where do we stand? The example of the Fontan procedure. Ann Biomed Engineer. 2016;44:174-86.

18. Lee N, Taylor MD, Banerjee RK. Right ventricle-pulmonary circulation dysfunction: a review of energy-based approach. Biomed Engineer Online. 2015;14:S8.

19. Pediatric echo z-score calculator for the main pulmonary artery (MPA), right pulmonary (RPA), and left pulmonary arteries (LPA). Available at: http://www. parameterz.com/sites/pulmonary-arteries. Accessed April 1, 2019.

20. Kabinejadian F, Ghista DN. Compliant model of a coupled sequential coronary arterial bypass graft: effects of vessel wall elasticity and non-Newtonian rheology on blood flow regime and hemodynamic parameters distribution. Med Engineer Phys. 2012;34:860-72.
21. Bird R, Armstrong R, Hassager O. Dynamics of Polymeric Liquids, 1. New York, NY: Wiley; 1987.

22. Sequeira A. Hemorheology: non-Newtonian constitutive models for blood flow simulations. In: Farina A, Mikelić A, Rosso F, eds. Lecture Notes in Mathematics, 2212. New York, NY: Springer; 2018:1-44.

23. Ansys CFX. Available at: https://www.ansys.com/products/fluids/ansys-cfx. Accessed April 1, 2019.

24. Ebrahimi P. Patient-specific Design of the Right Ventricle to Pulmonary Artery Conduit via Computational Analysis. [master's dissertation]. Sydney, Australia: University of Sydney; 2019. Available at: https://sydney.primo.exlibrisgroup. com/permalink/61USYD_INST/1c0ug48/alma991031548812905106.

25. Mohammadi S, Belli E, Martinovic I, Houyel L, Capderou A, Petit J, et al. Surgery for right ventricle to pulmonary artery conduit obstruction: risk factors for further reoperation. Eur J Cardiothorac Surg. 2005;28: 217-22.

26. Alastruey J, Khir AW, Matthys KS, Segers P, Sherwin SJ, Verdonck PR, et al. Pulse wave propagation in a model human arterial network: assessment of 1-D viscoelastic simulations against in vitro measurements. J Biomech. 2011;44:2250-8.

Key Words: computational fluid dynamics, congenital heart disease, right ventricular outflow tract, in silico design, flow optimization, mathematical modeling 


\section{APPENDIX 1. STRUCTURAL ANALYSIS OF INITIAL AND MODIFIED GEOMETRIES}

To account for deformability of the artery wall and its effect on the wall shear stress, 1-way fluid solid interaction analysis was performed on initial and modified geometries of each patient. The pressures resulting from computational fluid dynamics simulations were imported as loads and fixed supports were applied at both ends of the conduit. An automatic thin sweep mesh method with solid shell elements was employed. The meshing for a current clinicallyused conduit for one patient is shown in Figure 10.

To demonstrate the influence of the geometry modification, it was assumed that the same material as the current clinically used conduit will be used for the proposed modified conduit. The mechanical properties of this material were selected to replicate the human pulmonary artery wall. Our group has previously shown that the tensile modulus is $1.69 \mathrm{MPa}$, and the Poisson's ratio value of $0.5 .^{26}$ Total deformation and equivalent (von-Mises) stress at the beginning of a cardiac cycle, which shows a typical time, are calculated and shown in Figures 11 and 12. A significant reduction of these variables for all modified geometries is evident from these figures. This reconfirms the previously made conclusions. 


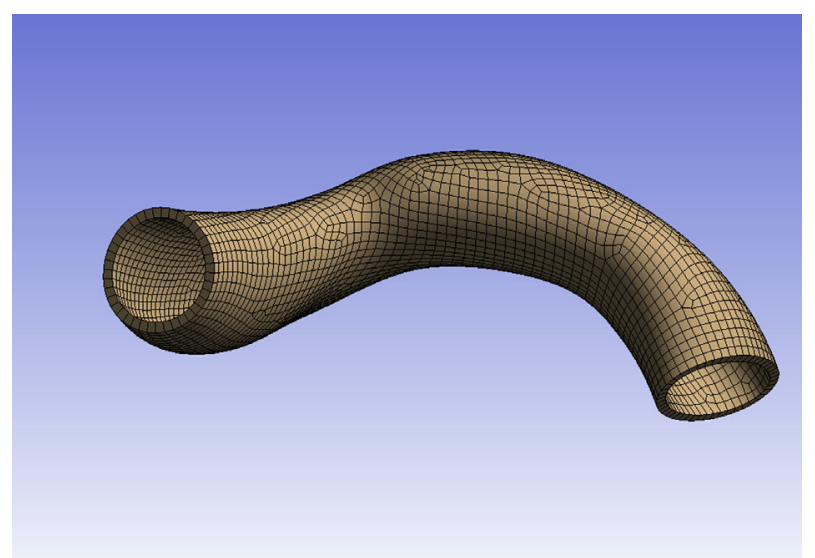

FIGURE 10. Typical shell mesh shown for the initial conduit of 1 patient. 


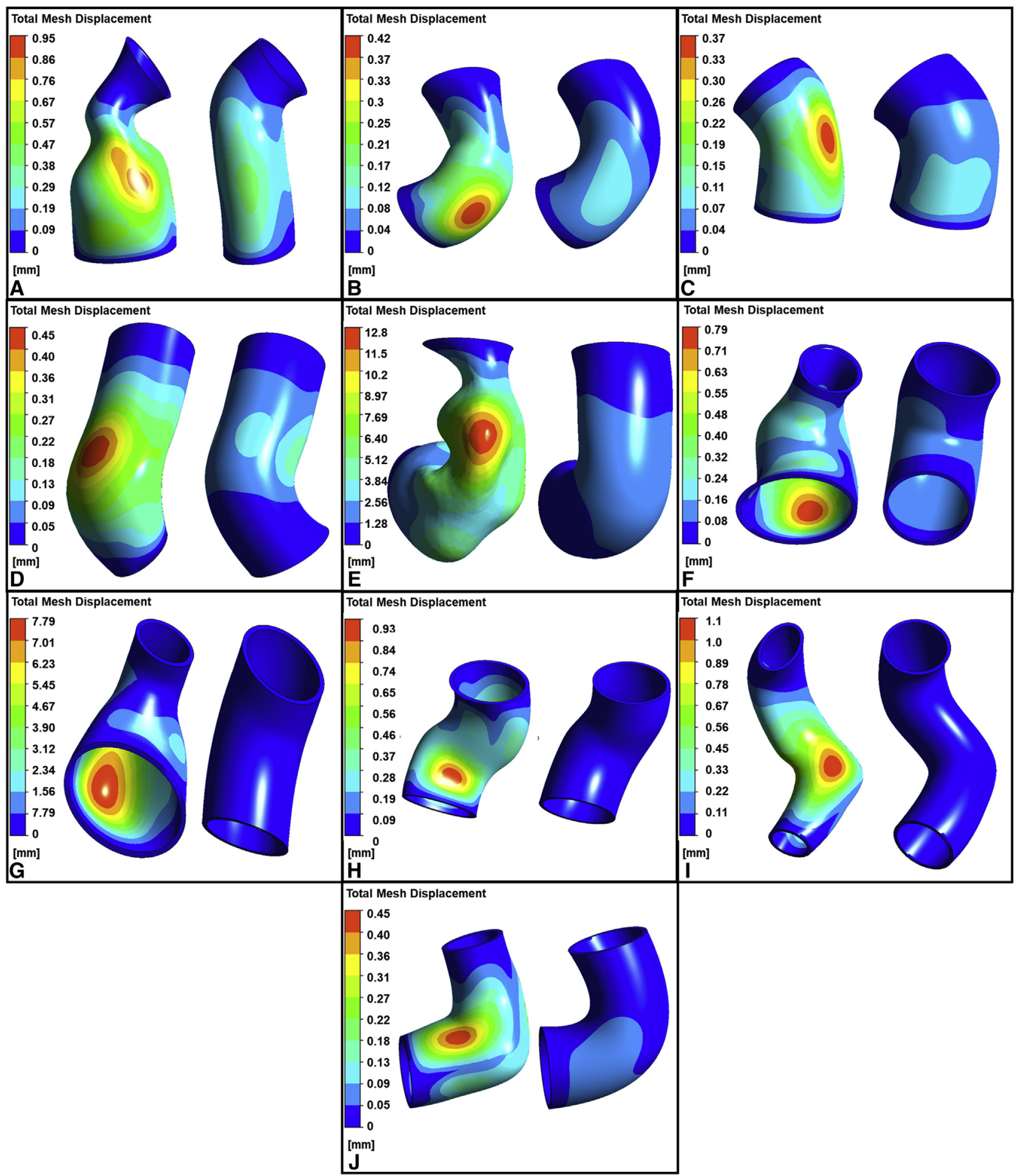

FIGURE 11. Comparison of the conduit wall deformation for patients A through J. Left, The initial geometry. Right, Modified geometry. 


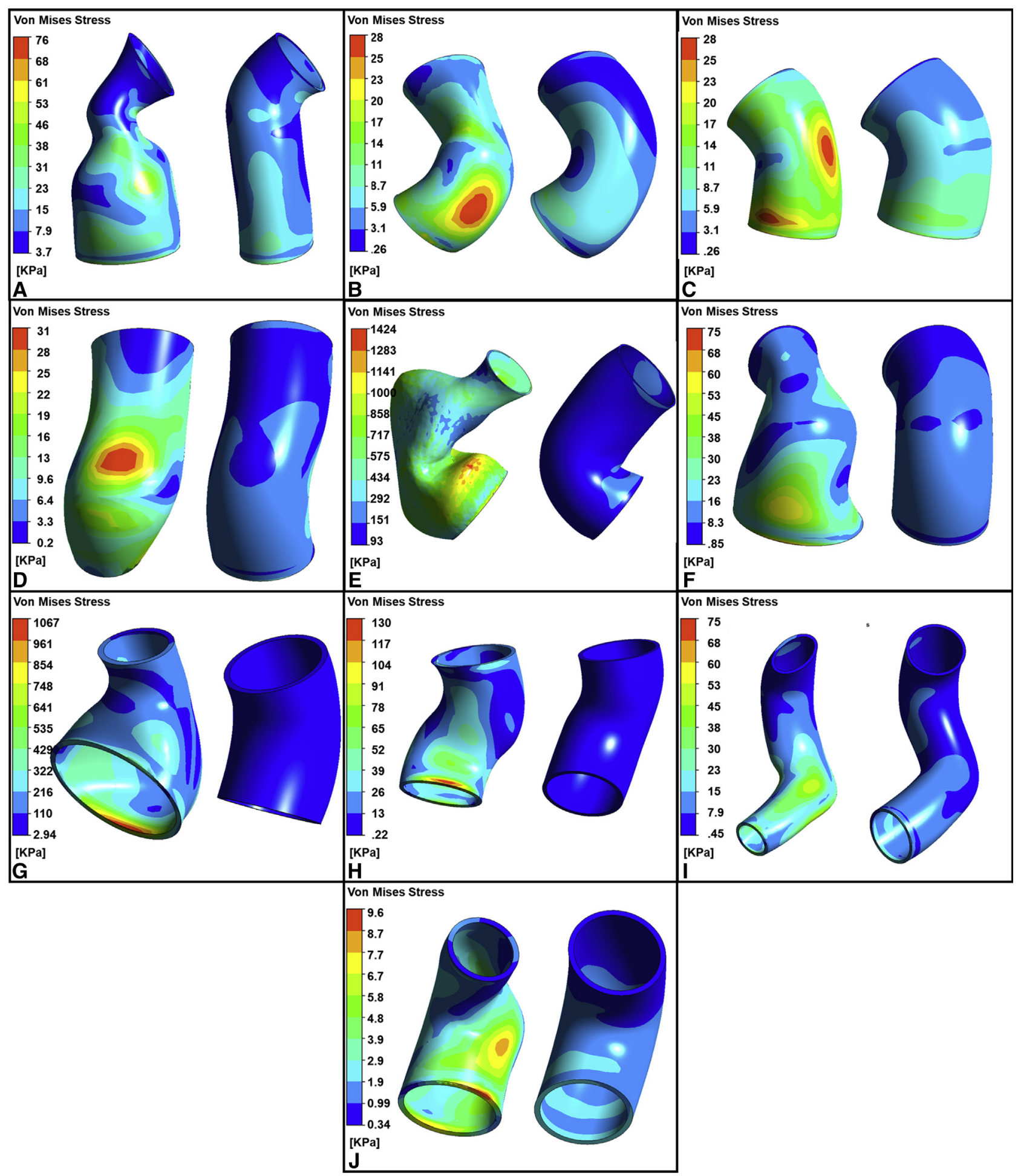

FIGURE 12. Comparison of the equivalent stress plotted on the conduit wall for patients A through J. Left, Initial geometry. Right, Modified geometry. 